\title{
Daten zur Geschichte und Baugeschichte der Katharinenkirche
}

225 Verleihung des Stadtrechts für Oppenheim durch den Reichsverweser Erzbischof Engelbert von Köln.

1226 Bestätigung des Stadtrechts durch Kaiser Friedrich II., Steuerprivileg.

1226 (?) Gründung von St. Katharinen als Filialkirche der Oppenheimer Pfarrkirche St. Sebastian.

1234 Ablaßspenden für St. Katharinen durch deutsche und französische Bischöfe (unverbürgt).

I258 Endgültige Festlegung der Diözesangrenzen zwischen Mainz und Worms, die Burgstadt mit St. Katharinen kommt zu Mainz, die Talstadt mit St. Sebastian bleibt bei Worms. Loslösung der Katharinenkirche von St. Sebastian und Erhebung zur Pfarrkirche durch Erzbischof Gerhard von Mainz und König Richard von Cornwallis.

129 I Erwähnung einer, fabrica parrochiae bei St. Katharinen.

I315 Verpfändung Oppenheims durch Ludwig den Bayern an das Erzstift Mainz.

I 3 I7 Gründung eines Kollegiatstiftes für 12 Kanoniker an St. Katharinen.

I 317 Beginn von Bauarbeiten an der Südseite des Langhauses (Bauinschrift).

$1332 / 33$ Verglasung der Ostrose.

I 324, I340,

1 359, 1361 Altarstiftungen für das Langhaus.

I4I 4 Verdingung von Meister Madern, dem Steinmetzen (Madern Gerthener aus Frankfurt), wohl für den Bau des Westchors.

1439 Weihe des Westchors.

1565 Aufhebung des Stiftes durch Kurpfalz.

1689 Einäscherung Oppenheims durch französische Truppen, Brand der Dächer der Katharinenkirche.

I703 Einsturz des Gewölbes des Westchors.

I 835-38 Restaurierung unter Ignaz Opfermann.

1879-89 Restaurierung unter Friedrich und Heinrich von Schmidt.

1934-37 Restaurierung unter Paul Meißner, Bau des neuen Westchorgewölbes.

Seit 1957 Einrichtung einer ständigen Bauhütte an St. Katharinen, Restaurierung der Südseite des Langhauses. 
